\title{
Primary ovarian pregnancy: case report and review of literature
}

\author{
Sarah Hassan, ${ }^{1}$ Rohit Arora, ${ }^{2}$ Kalsang Bhatia ${ }^{3}$ \\ ${ }^{1}$ Department of Surgery, Royal Albert Edward Hospital, Preston, UK \\ ${ }^{2}$ Department of Obstetrics and Gynaecology, Wythenshawe, Manchester, UK \\ ${ }^{3}$ Department of Obstetrics and Gynaecology, Burnley General Hospital, Burnley, UK \\ Correspondence to Dr Sarah Hassan, sah87@doctors.net.uk
}

\begin{abstract}
Summary
A young woman in her 20s presented with sudden onset right-sided abdominal pain. On examination she was tender in the right adnexae. Her urine pregnancy test was positive and $\beta H C G$ value was 1862. Abdominal and pelvic ultrasound revealed evidence of a significant right-sided adnexal mass, a small amount of peritoneal-free fluid and an empty uterus. The decision was made to proceed with laparoscopy in view of mass size and the presence of fluid in the pelvis. Conservative resection of the gestational sac was performed and the patient made an uneventful recovery. Histology was consistent with ovarian ectopic pregnancy.
\end{abstract}

\section{BACKGROUND}

This case illustrates the nature of ovarian pregnancy in the potential to conceal itself within a number of diagnoses. It highlights the preoperative and intraoperative features that should raise the clinician to suspect ovarian pregnancy as a primary diagnosis. Literature confirms that despite advances in imaging and laboratory testing, ovarian pregnancy remains a histopathological diagnosis.

\section{CASE PRESENTATION}

A young woman in her 20s presented to the emergency department complaining of sudden onset right-sided abdominal pain with nausea. She had no associated urine/ bowel symptoms and no vaginal bleeding/discharge. Her last menstrual period was 4 weeks ago. The patient had one previous pregnancy 8 years ago which was delivered by emergency caesarean section in view of placental abruption.

On examination, there were no clinical signs of circulatory collapse and the abdomen was soft but tender on palpation of the right iliac fossa with no guarding or rebound symptoms. No masses were felt on palpation of the abdomen. Speculum examination showed no evidence of bleeding; the cervix was mildly congested and the external os was closed. No excitation was elicited on bimanual vaginal examination. The uterus was normal in size and there was no bogginess on palpation of the pouch of Douglas. There was no obvious palpable adnexal mass.

\section{INVESTIGATIONS}

Urine pregnancy test was positive. Biochemical and haematological investigations were mainly normal but $\beta \mathrm{HCG}$ was raised at 1862 .

Transvaginal ultrasound illustrated an anteverted uterus with endometrial thickness $3.4 \mathrm{~mm}$. There was no evidence of intrauterine pregnancy. A right-sided heterogenous mass measuring $50 \times 39 \times 56 \mathrm{~mm}$ was seen indenting into the uterine cavity suggestive of a rightsided cornual ectopic pregnancy.

\section{DIFFERENTIAL DIAGNOSIS}

In view of the age of the patient and sudden onset of symptoms, the initial impression was that two important causes of right iliac fossa pain should be excluded: appendicitis and ectopic pregnancy. However, because of this patient's clinical picture, the index of suspicion for appendicitis was low. Her observations were stable and she was apyrexial. Her inflammatory markers were normal which suggested an unlikely appendicitis but this could not be indefinitely excluded at this stage.

The $\beta$ HCG was raised which narrowed the differential diagnosis significantly and the working diagnosis was an ectopic pregnancy until proven otherwise. As common conditions are common, the most likely diagnosis was a tubal ectopic; however, an ovarian ectopic should be considered within the differential.

\section{TREATMENT}

In view of mass size and the presence of peritonealfree fluid, the patient was consented for diagnostic laparascopy + salpingotomy \pm salpingectomy. Laparascopy revealed a normal sized uterus and normal left tube and ovary. The right tube was also normal, but the right ovary appeared enlarged with a haemorrhagic appearance (figure 1). Blood was present in the peritoneum (figure 2). In consideration of laboratory findings, the suspected diagnosis was ovarian ectopic pregnancy. The ovary was preserved and the mass was enucleated via linear incision using monopolar scissors and aqua dissection of contents (figure 3). Diathermy was used to secure haemostasis (figure 4). Samples were sent for histology and showed evidence of chorionic villi, decidua and fragments of corpus luteum. 


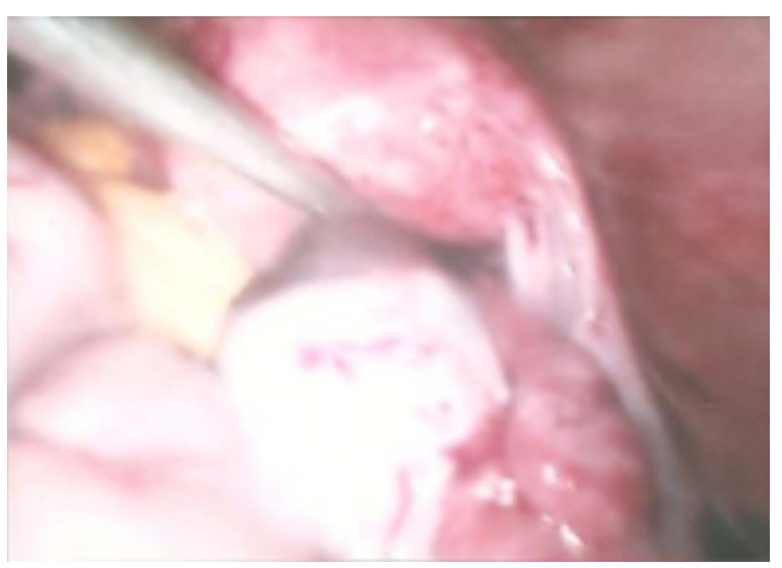

Figure 1 Right-sided ovarian ectopic pregnancy.

\section{OUTCOME AND FOLLOW-UP}

The patient had an uneventful recovery. BHCG was repeated on days 3 and 7 at which they were 158 and 6, respectively. The patient went on to conceive soon after.

\section{DISCUSSION}

Primary ovarian pregnancy remains a condition of low incidence rates, accounting for only $3 \%$ of all ectopic pregnancies. ${ }^{1}{ }^{2}$ Actual incidence rates are reported as $1 / 7000$ pregnancies. ${ }^{3}$ Whether this is an underestimation remains to be seen as there is a high likelihood that many pregnancies resolve spontaneously, ${ }^{4}$ as is known to occur in tubal ectopics.

It is thought that we may see a rise in ovarian pregnancy rates in coming years as a result of increasing clinical suspicion and improving diagnostic tools such as the use of transvaginal ultrasound. Comstock et al ${ }^{1}$ reviewed six cases of ovarian pregnancy to look at ultrasonography results and identify common findings between the cases. The study demonstrated a common feature in five of six patients: A hypoechogenic ring was seen on/within the surface of the ovary. Only one of these contained a yolk sac. The patient in which this finding was not seen was found to have a ruptured ectopic at surgery.

The difference between ultrasonographic appearance of a corpus luteum and ovarian pregnancy is that while both have a ring-like appearance, in the majority of cases, a

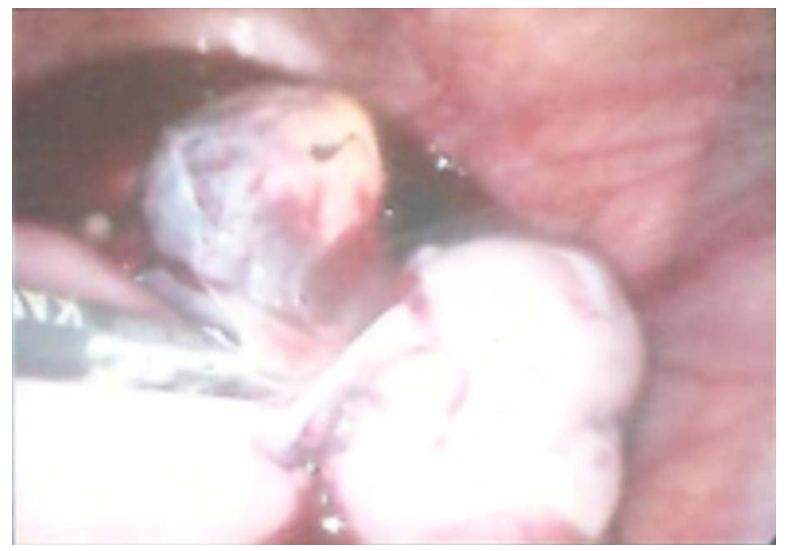

Figure 2 Blood present in the peritoneum.

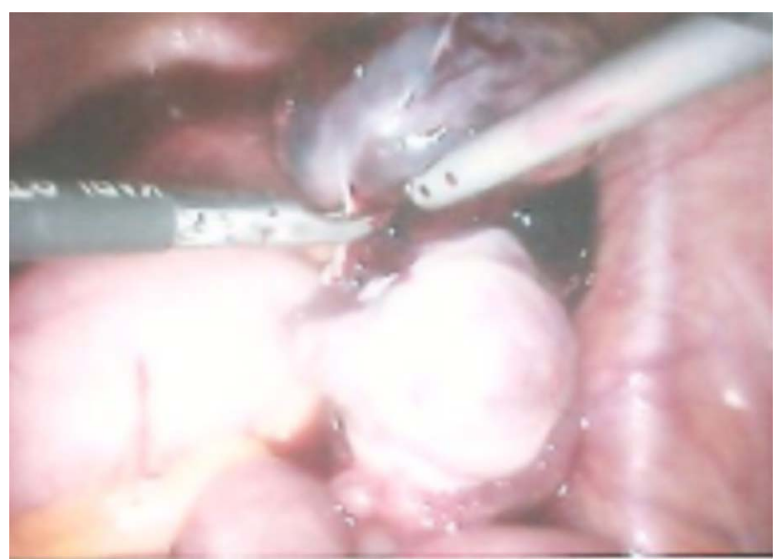

Figure 3 Dissection of the ovarian pregnancy using monopolar scissors.

corpus luteum appears less echogenic than the ovary itself. This is in contrast to an ovarian pregnancy in which the ring-like structure appears more echogenic than the ovary. ${ }^{1}$ However, there remains overlap between the two which results in laparoscopy continuing to be the gold standard of diagnosis. ${ }^{14}$ This is attributed to the fact it enables a histological diagnosis. Hallat ${ }^{5}$ confirms this in his study of 25 cases of ovarian pregnancy where he reports that a correct diagnosis at surgery was only made in $28 \%$ cases. The study correctly highlighted the difficulty in distinguishing between an ovarian pregnancy and a haemorrhagic cyst/corpus luteum by the naked eye.

The need for histology is confirmed by Spielberg's criteria for diagnosis. ${ }^{6} 7$

- The fallopian tube, including the fimbria ovarica, is intact and clearly separate from the ovary.

- The gestation sac occupies the normal position of the ovary.

- The gestation sac should be connected to the uterus by the ovarian ligament.

- There must be ovarian tissue attached to trophoblastic tissue in the specimen.

Although widely acknowledged that it is a clinically difficult diagnosis, there are certain risk factors and clinical signs that should rouse a high index of suspicion. ${ }^{8}$

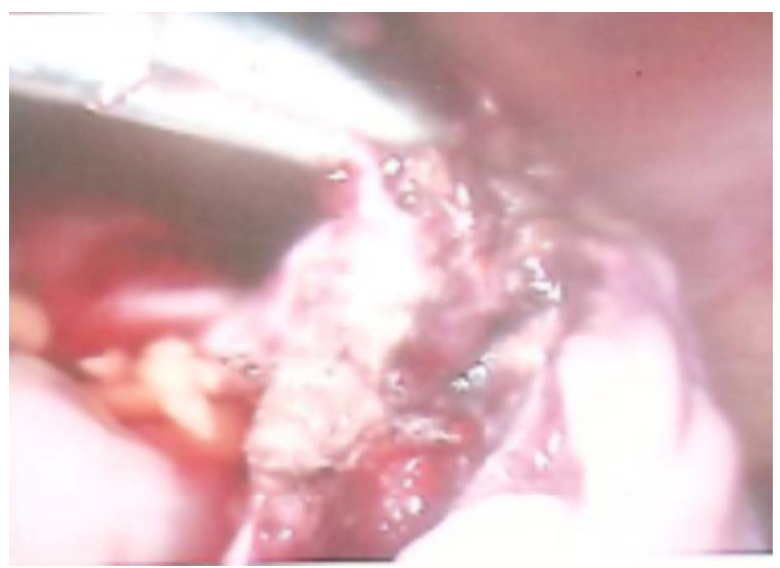

Figure 4 Haemostasis achieved with diathermy. 
A clinical triad of signs and symptoms has been reported in a number of cases: PV bleeding, abdominal pain and a palpable pelvic mass. ${ }^{1}$ However, these symptoms alone can present in a number of clinical conditions, therefore do not point to a diagnosis. Accompanying factors to look out for are symptoms of amenorrhoea and a raised $\beta \mathrm{HCG}>1000 \mathrm{IU}^{8}$ If an empty uterus is seen on ultrasound the diagnosis is confirmed as a pregnancy of unknown location. Scholars may argue that the differential between a tubal and ovarian pregnancy prior to surgery is of academic value only, as it has no influence on management.

Other factors to be aware of are risks that can increase likelihood of ovarian pregnancy. Interestingly, there appears to be a strong association between women using an IUCD and the rates of ovarian pregnancy. ${ }^{1} 9$ One study illustrated that, in $68 \%$ cases of ovarian pregnancy, the patient had an intrauterine contraceptive device. ${ }^{2}$ The mechanism behind this remains unknown. More importantly, reports have shown that risk factors of ovarian pregnancy do not coincide with those reported in patients with tubal pregnancies. In fact, reports have shown that a high number of cases of ovarian pregnancies have occurred in fertile, multiparous women and environmental factors that favour tubal pregnancies such as pelvic inflammatory disease, previous surgery and a history of infertility are very rare in ovarian pregnancies. ${ }^{9}$ It is for this reason that management of ovarian pregnancy has evolved, teaching more conservative surgical methods. Previously, it was common for management to involve oopherectomy ${ }^{2}$ but recent reports have shown increased rates of conservative management. Many studies describe approaches of a wedge resection ${ }^{4}$ ovarian cystectomy/enucleation of the mass by blunt dissection of the trophoblastic tissue achieving haemostasis by thermal coagulation ${ }^{10}{ }^{11}$ or repair with vicryl. ${ }^{12}$ Seinera et al highlights the benefits of thermal coagulation in that, by producing a slow response, it decreases the destruction of follicular units avoiding unnecessary superficial ovarian injury. ${ }^{11}$ This leads to preserved ovarian function maintaining fertility in these women in which the risk of recurrence is no higher than the average female. There have been no reported cases of recurrent ovarian pregnancy thus far. ${ }^{4} 12$ This makes justification of more radical surgical procedures difficult, except in circumstances where complications arise.

The role of medical management in ovarian pregnancy remains a grey area. Similarly to tubal ectopics, ovarian pregnancies can be managed with methotrexate subject to inclusion criteria according to the Greentop Guidelines. The main criteria advise that there must be no signs of haemodynamic compromise and no evidence of blood in the pelvis. ${ }^{13}$ The size of the pregnancy must be less than $3.5 \mathrm{~cm}$ with no fetal heart. BHCG levels should be less than 3500 units. Given that diagnosis cannot be ascertained prior to diagnostic laparoscopy, it can be argued that if an invasive procedure is required to confirm diagnosis, definitive surgical management should be accomplished at the same time. ${ }^{10}$ This remains the subject of debate between experts.

\section{Learning points}

- Always conduct a pregnancy test in a woman with abdominal pain.

- In addition to Spielberg's criteria, there are other factors which can increase clinical index of suspicion.

- Risk factors of ovarian pregnancy are different to those of tubal pregnancies.

- At surgery, the appearance of a haemorrhagic cyst should alert the clinician to the possibility of an ovarian pregnancy.

- Conservative surgical management should be sought out to maintain fertility in these patients.

Competing interests None.

Patient consent Obtained.

\section{REFERENCES}

1. Comstock C, Huston K, Lee W. The ultrasonographic appearance of ovarian ectopic pregnancies. Am College Obstet Gynaecol 2005;105:42-5.

2. Tinelli A, Hudelist G, Malvasi A, et al. Laparascopic management of ovarian pregnancy: case report. JSLS 2008;12:169-72.

3. Nwanodi 0, Khulpateea $\mathrm{N}$. The preoperative diagnosis of primary ovarian pregnancy: case report. J Natl Med Assoc 2006;98:796-8.

4. Sidek S, Lai SF, Lim-Tan SK. Primary ovarian pregnancy: current diagnosis and management. Singapore Med J 1994;35:71-3.

5. Hallat J. Primary ovarian pregnancy a report of twenty-five cases. $A m \mathrm{~J}$ Obstet Gynecol 1982;143:50-60.

6. Nadarajah S, Sim LN, Loh SF. Laparascopic management of an ovarian pregnancy. Singapore Med J 2002;43:95-6.

7. http://bestpractice.bmj.com Updated Jun 2011

8. Sergent $\mathbf{F}$, Mauger-Tinlot $F$, Gravier $A$, et al. Ovarian pregnancies: revaluation of diagnostic criteria. J Gynecol Obstet Biol Reprod (Paris) 2002;31:741-6.

9. Marret H, Hamamah S, Alonso A-M, et al. Case report and review of the literature: primary twin ovarian pregnancy. Human Reprod 1997;12:1813-15

10. Einenkel J, Baier D, Horn L-C, et al. Laparascopic therapy of an intact primary ovarian pregnancy with ovarian hyperstimulation syndrome: case report. Human Reprod 2000;15:2037-40.

11. Seinera P, Di Gregorio A, Riccardo A, et al. Ovarian pregnancy and operative laparascopy: report of eight cases. Human Reprod 1997;12:608-10.

12. Farghaly M, Saeed M. Primary ovarian pregnancy. ASJOG 2005;2:297-9.

13. RCOG Guideline No 21 May 2004 Reviewed 2010. 


\section{BMJ Case Reports}

Copyright 2012 BMJ Publishing Group. All rights reserved. For permission to reuse any of this content visit http://group.bmj.com/group/rights-licensing/permissions.

BMJ Case Report Fellows may re-use this article for personal use and teaching without any further permission.

Please cite this article as follows (you will need to access the article online to obtain the date of publication).

Hassan S, Arora R, Bhatia K. Primary ovarian pregnancy: case report and review of literature. BMJ Case Reports 2012;10.1136/bcr-2012-007112, Published XXX

Become a Fellow of BMJ Case Reports today and you can:

- Submit as many cases as you like

- Enjoy fast sympathetic peer review and rapid publication of accepted articles

- Access all the published articles

- Re-use any of the published material for personal use and teaching without further permission

For information on Institutional Fellowships contact consortiasales@bmjgroup.com

Visit casereports.bmj.com for more articles like this and to become a Fellow 